2-1-2021

\title{
Family Demography in the Post-Covid Era
}

Clémentine Rossier

Follow this and additional works at: https://knowledgecommons.popcouncil.org/series_pdr_essays-covid How does access to this work benefit you? Let us know!

\section{Recommended Citation}

Rossier, Clémentine. "Family Demography in the Post-Covid Era." In Covid-19 and the Global Demographic Research Agenda, edited by Landis MacKellar and Rachel Friedman, 59-63. New York: Population Council, 2021. 


\title{
Family Demography in the Post-Covid Era
}

\author{
ClÉMENTINe RossieR
}

IN THEIR EFFORTS to curb the Covid-19 pandemic, many of the world's governments restricted the movements and activities of people for several months, severely disrupting their daily practices and often cutting them off from routine opportunities and resources. Many people adjusted to these losses by shifting goals, tapping into alternative resources, and coping as well as they could with the collective wave of panic that swept through the media. The health crisis also pushed a vulnerable fringe further into dispossession and precarity, and the pandemic probably widened psychological and social inequalities already present at the population level.

In fact, Covid-19 acted just like other adverse life events such as illnesses, divorces, losing one's job or partner. Demographers know that depending on their preexisting resource endowments, individuals are not equally equipped to cope with crises, and that adverse events have potentially lasting effects on socioeconomic conditions and well-being. Even nondisruptive life events like union formation entertain strong links with inequalities, as betterendowed individuals find it easier to enter into unions, and are more apt at reaping their long-term benefits.

Demographers have studied life events and their links to different forms of inequalities for many decades. In the field of family and reproduction, they have recently monitored trends in teenage pregnancies, "digital mating," civil partnerships, higher-order unions, divorce among older adults, LGBT pathways to parenthood, twin and triplet births, late motherhood, transition to grandparenthood, and so forth, and have examined their relationship with socioeconomic conditions and the well-being of different family members. In line with the disciplinary canon of demography, they have analyzed the age, period, and cohort effects of these events in great detail.

In the post-Covid-19 era, family demographers will probably continue doing just that: they will look at the relationships between the health crisis and the numerical trends in diverse reproductive events, along with its complex age, period, and cohort impacts. Has the Covid-19 pandemic accelerated

Clémentine Rossier, Institute of Demography and Socioeconomics, University of Geneva.

POPULATION AND DEVELOPMENT REVIEW I ESSAYS (FEBRUARY 2021) 
the diffusion of new types of family events, such as meeting a partner online? Has it increased the incidence of divorce? Have these societal disruptions delayed fertility decisions, and will there be a subsequent catch-up process? Has access to family planning or abortion services been affected, leading to a surge in unplanned pregnancies and births? And will the pandemic have scarring effects? That is, will we witness Covid-19 cohorts of confined children with a different outlook on life and new demographic behaviors, or Covid-19 cohorts of young adults lastingly affected by the particular way in which they made their first steps into the world of employment or intimate relationships?

But the Covid-19 crisis will perhaps also help push the interdisciplinary life course approach more firmly to the center of demography, leading to a rethink of the research agenda. A central notion of the life course perspective is that the unfolding of individual lives, punctuated by diverse life events, is strongly shaped by societal contexts and crises (Elder 1998). The main idea of this approach is that society-wide events and conditions have knock-on effects for individuals, affecting the ordering and timing of their life events, and that (sometimes small) changes can have lasting effects in later life because of path-dependency, accumulation processes, and turning points. It also focuses on the large variations_-and the strong interconnectedness-between individuals. In other words, the life course perspective provides a blueprint, a systematic framework for studying the effects of major crises on individual and family life events and for understanding how they tie in with the varied dimensions of inequality (Bernardi et al. 2019).

By shifting their gaze toward this interdisciplinary research stream, demographers could integrate more actively some of the latest developments in the sociology and psychology of the life course. Like sociologists, they could pay attention to age effects as a manifestation of socially constructed age norms and institutions, as they do for gender differences (Levy and Bühlmann 2017). They could examine life events as potential watersheds where individuals move into paths of upward or downward social mobility, through gatekeeping and social reproduction processes (Buchmann and Steinhoff 2017). Demographers could simultaneously examine these life trajectories from the perspective of developmental psychology (Baltes et al. 2007) or through the lens of aging processes (Cullati et al. 2018). They could integrate these different disciplinary streams by turning to agency-within-structure meta-theories, where collective expectations and constraints confront individuals' sense of self and aspirations.

While the notion of identity has been a popular junction point for sociologists since Giddens, and while the Theory of Conjectural Action for fertility and family change (Johnson-Hanks et al. 2011) convincingly elaborates upon the interplay between structures and individual-level circumstances, such constructions can still be extended at the inner-individual level. I was especially convinced by the integration of elements of the psychology of 
motivation in life course research (Heckhausen and Buchmann 2019). This theoretical approach delves deeper into the (non)integration of social norms and values by individuals in the form of personal goals; it documents the conditions in the immediate environment (autonomy, affiliation, competence) that are needed by individuals to set and pursue goals maximizing their emotional well-being and other outcomes (Deci and Ryan 2008).

By widening the theoretical basis of life course processes from an interdisciplinary perspective, demographers would shift their attention to the resources and obstacles of all kinds that determine how individuals manage (or not) to deal with both society-wide crises like the Covid pandemic, and disruptive family events. In this perspective, family demographers could take a fresh look at family forms (often studied rather descriptively as consequences of family events) by considering them as sets of relational constraints and resources. They could ask how family relations are different in this regard compared to other close relationships, which would extend their reach into the study of extra-household and subjectively defined family forms (Widmer et al. 2013; Seltzer 2019). Different types of exchanges (care, socioeconomic, social influence, symbolic) and practices (sexuality, reproduction, cohabitation, cultural transmission, rites and rituals, and so forth) inherent to family ties across a diverse range of network members could be tracked more systematically. The relational adaptation of individuals and their changing inner circles could also be studied more fully using longitudinal study designs. The extent to which life events in other domains (residential mobility, working career, and so forth) lead to turnover of close and family relations could be examined in more depth. Other possible topics include the role of extended kinship ties and other weak relations in providing reservoirs of close relations, and the impact of spatiality, information, communication, and mobility technology on all of the above. Thanks to this additional knowledge, the role of families as matrices of resources or constraints for coping (or failing to cope) with various crises could be examined more thoroughly.

These advances would help demographers participate more actively in the discussion on indicators of human welfare used as governance tools at both national and international levels (the Sustainable Development Goals, for example). With the move away from income as the sole indicator of success, other markers of quality of life gained ground, including life expectancy and education in the early 1990s (the Human Development Index), followed by other measures of population health, including subjective or emotional well-being as stated in Goal 3 of the SDGs. Indicators of social affiliation (notably measures of potential support and of social participation) now also feature on the latest dashboards, especially in wealthier nations. In the framework of these discussions, family demographers should be in a position to contribute their expertise on the measure of meaningful relationships; shifting their attention to families not only as forms but as sets of resources and constraints should help them do just that. 
This issue brings us to another point: sustainable human welfare. While health crises like the Covid-19 pandemic may have temporarily overshadowed concerns about the deterioration of our physical environment by suddenly depriving people of their routine resources, it also prefigures the changes that will probably be needed to bring individual consumption into line with planetary limits. Gaining in-depth knowledge of how individuals function well in constrained environments, including by relying more, or differently, on relational resources, will be a key research area for the next decade. This is probably a factor behind the current interest in subjective (or emotional) well-being in the social sciences in general, and also in family demography. Indeed, rather than aiming at ever longer lives or greater wealth, which all come with major societal and environmental costs, putting "wellbeing" for all at the core of governance may be the only way to engage the transition toward sustainability (Gough 2017).

In a first book on human need published in 1991 with the philosopher Len Doyal, Ian Gough (Doyal and Gough 1991), a social policy specialist, argued that societies should strive to provide a minimum level of intermediary needs satisfaction to all (civil rights, nutrition, shelter, protection, health care, education, significant others, decent work, and so forth), which in turn will allow them to maximize their current physical and mental health (basic human needs). As opposed to Maslow's crude theory, this frame does not posit a hierarchy of needs (none has to be met first): the distinction introduced simply reflects a specific localization, basic needs satisfaction occurring at the inner individual level and intermediary needs satisfaction through individuals' interactions with their immediate environment.

Moreover, while needs are arguably universal, Doyal and Gough (1991) stress that the ways to satisfy them are eminently context-specific. Gough (2017) links human need satisfaction to sustainability: to him, focusing on minimally satisfying these intermediary needs for all—while a colossal challenge for humanity-will help in implementing the structural changes needed to drastically curb environmentally demanding practices among wealthier countries and social groups while promoting social justice. Here, well-being (basic need satisfaction) acts as a central yardstick, as a high level of well-being can be maintained in the long-term even when limiting nonsustainable consumption; but the needed conditions-collective representations and publicly provided services probably play a key role-remain to be elucidated. Family demographers may have much to say about the role of relational resources and social participation in bringing about change in consumption patterns and in making up for the decline in environmentally costly activities involved in the production of well-being. 


\section{References}

Baltes, P.B., U. Lindenberger, and U.M. Staudinger. 2007. "Life span theory in developmental psychology," in R.M. Lerner and W. Damon (eds.) Handbook of Child Psychology: Theoretical Models of Human Development, pp. 569-664. John Wiley \& Sons.

Bernardi, L., J. Huinink, and R.A. Settersten, Jr. 2019. "The life course cube: A tool for studying lives," Advances in Life Course Research 41: 100258.

Buchmann, M. and A. Steinhoff. 2017. "Social inequality, life course transitions, and adolescent development," Journal of Youth and Adolescence 46(10): 2083-2090.

Cullati, S., M. Kliegel, and E. Widmer. 2018. "Development of reserves over the life course and onset of vulnerability in later life," Nature Human Behaviour 2(8): 551-558.

Deci, E.L. and R.M. Ryan. 2008. "Self-determination theory: A macrotheory of human motivation, development, and health," Canadian Psychology 49(3): 182.

Doyal, L. and I. Gough. 1991. A Theory of Human Need. Macmillan.

Elder, Jr., G.H. 1998. “The life course as developmental theory," Child Development 69(1): 1-12.

Gough, I. 2017. Heat, Greed and Human Need: Climate Change, Capitalism and Sustainable Wellbeing. UK, USA: Edward Elgar Publishing Limited.

Heckhausen, J. and M. Buchmann. 2019. "A multi-disciplinary model of life-course canalization and agency," Advances in Life Course Research 41: 100246.

Johnson-Hanks, J.A., C.A. Bachrach, S.P. Morgan, and H.P. Kohler. 2011 . Understanding Family Change and Variation: Toward a Theory of Conjunctural Action (Vol. 5). Springer Science \& Business Media.

Levy, R. and F. Bühlmann. 2016. "Towards a socio-structural framework for life course analysis," Advances in Life Course Research 30: 30-42.

Seltzer, J.A. 2019. "Family change and changing family demography," Demography 56(2): $405-426$.

Widmer, E.D., G. Aeby, and M. Sapin. 2013. “Collecting family network data," International Review of Sociology 23(1): 27-46. 